\title{
Ciclos Políticos e Resultados Eleitorais: Um Estudo sobre o Comportamento do Eleitor Brasileiro*
}

\author{
Marcos Yamada Nakaguma ${ }^{\dagger}$, Siegfried Bender ${ }^{\ddagger}$
}

Conteúdo: 1. Introdução; 2. Revisão da Literatura; 3. Metodologia Proposta;

4. Determinantes Políticos do Comportamento Fiscal dos Estados;

5. Comportamento do Eleitorado; 6. Conclusão.

Palavras-chave: Ciclos Políticos, Reeleição, Comportamento Eleitoral, Política Fiscal.

Códigos JEL: E62, H72.

O presente trabalho investiga as causas determinantes da existência de ciclos eleitorais na política fiscal dos estados brasileiros. Para tanto, propõe-se uma metodologia para decompor os ciclos políticos, procurando identificar as parcelas devidas ao oportunismo e à atividade sinalizadora dos governantes. O objetivo é investigar se, e em que medida, os eleitores são capazes de: (1) captar as sinalizações de competência emitidas pelos governantes; e (2) identificar e punir políticos oportunistas. O resultado principal é o de que o eleitorado recompensa a parcela oportunista dos ciclos, tanto nas receitas quanto nas despesas, embora este efeito tenha diminuído ao longo das eleições.

This paper studies the determinants of political budget cycles in the Brazilian federal states. We propose a methodology to decompose the political cycles into one part that is due to the opportunistic behavior and another one that is due to the signaling activity of incumbent governors. The goal is to investigate whether voters are able to: (1) capture the competence signals sent by governors; and (2) identify and punish opportunistic politicians. The results show that the Brazilian electorate rewards the opportunistic part of the cycles in both revenue and spending, although this effect has been decreasing over the elections.

\footnotetext{
* Os autores agradecem a Carlos Eduardo Soares Gonçalves, Marcio Issao Nakane, Ronald Hillbrecht e a um parecerista anônimo por comentários e sugestões valiosos. Agradecem, ainda, ao CNPq pelo apoio financeiro concedido a esta pesquisa. Todos os eventuais erros e omissões são de nossa inteira responsabilidade.

${ }^{\dagger}$ Columbia University. E-mail: myn2105@columbia.edu

‡Universidade de São Paulo. Rua Professor Luciano Gualberto, 908, Cidade Universitária, São Paulo, SP., CEP 05508-010. E-mail: sieg@usp.br
} 


\section{INTRODUÇÃO}

O presente trabalho investiga as causas determinantes da existência de ciclos eleitorais na política fiscal dos estados brasileiros. A evidência empírica internacional é a de que os déficits orçamentários se elevam e a tributação se reduz nos anos eleitorais, especialmente em países em desenvolvimento. ${ }^{1}$ Para o Brasil, diversos estudos têm demonstrado que o gasto público aumenta intensamente durante as eleições. ${ }^{2}$ De forma geral, porém, poucos trabalhos têm se dedicado a analisar os fatores que ensejam o surgimento destes ciclos, sendo que a reação do eleitorado em face destas manipulações tem sido pouco considerada pela literatura. Neste contexto, coloca-se a seguinte questão: Por que os ciclos eleitorais existem?

Um argumento implicitamente mantido por diversos trabalhos nesta literatura é o de que a constatação da existência de ciclos eleitorais bastaria para corroborar a idéia de que os ciclos servem para elevar a probabilidade de reeleição dos governantes; isto é, haveria uma relação de causalidade positiva entre ciclos e reeleição. No entanto, uma análise mais criteriosa deste argumento deixa claro que tal raciocínio deve ser encarado com certa ressalva. A priori, não haveria razão teórica alguma para esperar que os eleitores devessem recompensar manipulações oportunistas nas políticas públicas. Na realidade, considerando-se a restrição orçamentária intertemporal do governo, os ciclos eleitorais deveríam ser vistos como prejudiciais à economia, constituindo-se em um desvio desnecessário em relação à "trajetória ótima" dos gastos e do déficit público. ${ }^{3}$

A literatura teórica na área de economia política propõe duas explicações alternativas para o fenômeno dos ciclos eleitorais. De um lado, os modelos de ciclos políticos ressaltam a idéia de que as manipulações eleitoreiras servem para sinalizar a "competência administrativa" 4 dos governantes, uma vez que somente políticos realmente aptos seriam capazes de produzir tais ciclos. Por outro lado, os modelos de controle eleitoral enfatizam a possibilidade de que os ciclos eleitorais sejam induzidos, ao menos em parte, pela ausência de um monitoramento político adequado por parte dos eleitores, que, neste caso, seriam incapazes de identificar e punir manipulações fiscais oportunistas.

Persson e Tabellini (2003) colocaram a questão da seguinte maneira: "Ambos os modelos [ciclos políticos e controle eleitoral] prevêem cortes nos impostos antes das eleições. Porém, as predições em relação ao gasto diferem. Os modelos que enfatizam a construção de reputação, como Rogoff (1990), prevêem, na linha dos modelos tradicionais do tipo Nordhaus-Lindbeck, a elevação do dispêndio público, enquanto que os modelos que enfatizam o controle eleitoral, como Besley e Case (1995b), prevêem que o gasto decrescerá, pois parcela dele é vista como indesejável pelos eleitores".

A despeito das implicações contraditórias, é importante ressaltar a complementaridade existente entre ambos os modelos. De fato, cada um deles enfatiza um aspecto distinto da relação entre governantes e eleitores. Os modelos de ciclos políticos, por um lado, focalizam a questão de que os eleitores preferem governantes mais competentes e atribuem aos ciclos o papel de um mecanismo sinalizador de competência. Os modelos de controle eleitoral, por sua vez, partem da premissa de que os governantes são oportunistas ("rent-seekers") e analisam as eleições como um instrumento de controle à disposição dos eleitores. ${ }^{5}$ É neste sentido que se pode afirmar que, se, por um lado, as eleições estimulam os governantes a sinalizarem competência, conforme ressaltam os modelos de ciclos políticos, por outro

\footnotetext{
${ }^{1}$ Ver Alesina e Perotti (1995), Alesina et alii (1997), Drazen (2000, cap. 7), Olters (2001), Franzese (2002), Shi e Svensson (2003) e Persson e Tabellini (2003) para revisões desta literatura.

${ }^{2}$ Ver, por exemplo, Bittencourt e Hillbrecht (2003), Nakaguma e Bender (2006) e Sakurai (2009).

${ }^{3}$ Esta idéia é consistente com os modelos de "optimal tax smoothing". Ver, por exemplo, Barro (1979).

${ }^{4}$ De acordo com Drazen (2000, p. 270), a idéia de "competência administrativa" deve ser interpretada como a capacidade do governante de lidar com uma determinada situação ou contexto político. Por exemplo, no caso de um governandor de estado, o termo poderia ser interpretado como a habilidade de interagir e aprovar políticas no legislativo.

${ }^{5} \mathrm{Em}$ termos teóricos, os modelos de ciclos políticos concentram-se na questão do "adverse selection", enquanto que os modelos de controle eleitoral concentram-se na questão do "moral hazard".
} 
lado, as eleições, como instrumento de controle, também atuam no sentido de limitar as manipulações eleitoreiras das políticas públicas.

O presente trabalho busca propor uma metodologia para decompor os ciclos eleitorais, procurando identificar as parcelas devidas ao oportunismo e à atividade sinalizadora dos governantes. 0 objetivo é investigar se, e em que medida, os eleitores são capazes de:

(1) captar as sinalizações de competência emitidas pelos governantes, em conformidade com os modelos de ciclos políticos; e

(2) identificar e punir políticos oportunistas, em conformidade com os modelos de controle eleitoral.

O trabalho segue estruturado da seguinte maneira: a próxima seção apresenta uma revisão geral da literatura; a seção 3 delineia os principais aspectos da metodologia utilizada neste estudo; as seções 4 e 5 analisam, de forma conjunta e interdependente, as relações entre política fiscal e eleições nos estados brasileiros; por fim, a seção 6 conclui o trabalho apresentando as principais conclusões.

\section{REVISÃO DA LITERATURA}

A literatura empírica sobre os determinantes do voto provê evidências de que o eleitorado em países desenvolvidos é "fiscalmente conservador", no sentido de que tende a punir políticas expansionistas, caracterizadas pela produção de déficits e pelo aumento de gastos e impostos. Em trabalho seminal, Peltzman (1992) mostrou que o eleitorado americano é avesso ao aumento do dispêndio público, independentemente da forma como este seja financiado. A elevação dos gastos às vésperas de eleições, em particular, apresenta um efeito especialmente negativo sobre o desempenho eleitoral, já que costuma estar associada a políticas ineficientes e oportunistas.

Mais recentemente, diversos trabalhos têm corroborado a idéia de "conservadorismo fiscal", sobretudo com relação às manipulações eleitoreiras. Brender (2003) verificou que a produção de déficits e o aumento da dívida em anos eleitorais diminui a probabilidade de reeleição em Israel, enquanto Brender e Drazen (2008) mostraram que os déficits eleitorais reduzem as chances de reeleição em "democracias antigas" e não exercem influência alguma sobre os resultados eleitorais em "democracias jovens". 6 Neste mesmo sentido, Mendes (2004), Sakurai (2005) e Sakurai e Menezes-Filho (2008) observaram que os ciclos políticos nas despesas não exercem impacto algum sobre as chances de reeleição nos municípios brasileiros.

A abordagem empregada pela maioria dos estudos consiste em estimar "regressões de voto" seguindo metodologia semelhante à utilizada por Peltzman (1992), Besley e Case (1995a) e Alesina et alii (1998). Estes autores consideraram o seguinte modelo:

$$
\text { voto }_{i t}=\delta_{1} \cdot \Delta \% y_{i t}^{\text {mandato }}+\delta_{2} \cdot \Delta \% y_{i t}^{\text {eleiçōes }}+\omega_{i t}^{\prime} \cdot \pi+\varepsilon_{i t},
$$

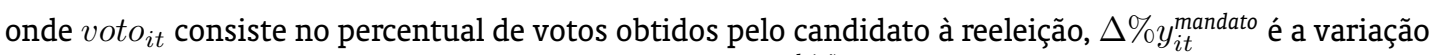
percentual da variável fiscal ao longo do mandato, $\Delta \% y_{i t}^{\text {eleicoes }}$ é a variação percentual da variável fiscal durante o ano eleitoral e $\omega_{i t}$ representa um vetor de variáveis de controle. Neste contexto, e em consonância com a idéia de conservadorismo fiscal, grande parte dos trabalhos têm obtido que os ciclos políticos não apresentam impacto algum sobre os resultados eleitorais, isto é, $\delta_{2}=0$.

É importante ressaltar, no entanto, que tal metodologia identifica a magnitude dos ciclos políticos com a simples variação dos instrumentos fiscais durante o período eleitoral, $\Delta \% y_{i t}^{\text {eleições }}$. Na realidade, porém, existem uma diversidade de fatores que interferem sobre a evolução das políticas públicas ${ }^{7}$, não

\footnotetext{
${ }^{6}$ Kraemer (1997) e Akhmedov e Zhuravskaya (2004) também mostraram que os déficits eleitorais não são recompensados na América Latina e na Rússia, respectivamente.

${ }^{7}$ Ver Romer e Romer $(2004,2009)$ para exemplos nas áreas da política monetária e fiscal.
} 
havendo, a princípio, nenhuma razão teórica para esperar que agentes racionais devam recompensar ou punir variações fiscais independentemente das causas que as tenham motivado.

Mais especificamente, as variações eleitorais podem ser decompostas em três principais fatores:

$$
\Delta \% y_{i t}^{\text {eliçöes }}=\underset{(\text { nulo })}{\text { previsto }_{i t}}+\underset{(-)}{\text { oportunismo }_{i t}}+\underset{(+)}{\text { competência }} i t+u_{i t},
$$

onde, de acordo com os modelos teóricos, cada um desses componentes apresenta um efeito esperado distinto sobre o voto, a saber: os eleitores devem punir a parcela oportunista dos ciclos, recompensar as sinalizações de competência e ser indiferentes em relação à parcela prevista - e devida a fatores econômicos fora do controle dos governantes - das variações fiscais.

Desta forma, a "metodologia tradicional" estaria restrita a identificar o efeito agregado dos ciclos políticos sobre as chances de reeleição dos governantes. De um ponto de vista teórico, porém, a evidência de que $\delta_{2}=0$ apresenta pouco significado econômico, já que os eleitores podem punir e recompensar parcelas diferentes de um mesmo ciclo. Neste sentido, a própria conclusão de que os eleitores são "fiscalmente conservadores", no sentido de serem avessos a políticas expansionistas independentemente das causas que as tenham motivado, poderia ser questionada em razão das imperfeições apresentadas pelo método utilizado.

\section{METODOLOGIA PROPOSTA}

A metodologia proposta por este trabalho baseia-se na idéia de que a elevação dos gastos públicos pode ser percebida pelos eleitores tanto como uma tentativa de sinalizar competência quanto como uma evidência de oportunismo por parte dos governantes. O fundamento teórico se encontra nos modelos de ciclos políticos racionais, assim como em Rogoff e Silbert (1988) e Rogoff (1990), e nos modelos de controle eleitoral, assim como em Barro (1979), Ferejohn (1986) e Besley e Case (1995b).

$\mathrm{O}$ trabalho segue estruturado em duas etapas. A primeira estuda os determinantes políticos do comportamento fiscal dos estados brasileiros, testando a existência de ciclos eleitorais nas variáveis orçamentárias. O seguinte modelo é estimado:

$$
y_{i t}=\sum_{j=1}^{L} \rho_{j} \cdot y_{i, t-j}+\text { political }_{i t}^{\prime} \cdot \delta+z_{i t}^{\prime} \cdot \pi+a_{i}+v_{i t},
$$

onde $y_{i t}$ representa o logaritmo da variável fiscal de interesse, political $l_{i t}$ representa um conjunto de variáveis políticas e eleitorais, $z_{i t}$ representa um conjunto de variáveis de controle, $a_{i}$ é um efeito-fixo não observado e $v_{i t}$ é um termo aleatório iid.

A segunda etapa analisa o comportamento do eleitorado em face dos ciclos eleitorais, considerando as explicações levantadas pelos modelos de ciclos políticos e pelos modelos de controle eleitoral. A metodologia utilizada consiste em dividir, com base nas estimativas obtidas em primeiro estágio, os resultados fiscais em três principais componentes:

(1) uma parcela prevista pelos agentes e devida a fatores que estão fora do controle dos governantes,

(2) uma parcela devida ao oportunismo eleitoral, e

(3) uma parcela residual, possivelmente refletindo a competência dos governantes.

A partir disso, pode-se estimar o efeito de cada um desses componentes sobre a probabilidade de reeleição dos governantes, de acordo com o seguinte modelo:

$$
\text { voto }_{i t}=\gamma_{1} \cdot \text { previsto }_{i t}+\gamma_{2} . \text { oportunismo }_{i t}+\gamma_{3} . \text { competência }_{i t}+\omega_{i t}^{\prime} \cdot \pi+\eta_{i}+\varepsilon_{i t}
$$


Esta metodologia permite testar o nível racionalidade dos eleitores, verificando se, de fato, eles são capazes de utilizar eficientemente todas as informações disponíveis para identificar o grau de oportunismo e de competência de seus governantes. A hipótese de racionalidade dos agentes implica, em primeiro lugar, que $\gamma_{1}=0$, pois o voto não pode ser afetado por variações fiscais decorrentes de fatores que independem da atuação dos governantes. Além disso, deve-se esperar que $\gamma_{2} \leq 0$, pois, em conformidade com os modelos de controle eleitoral, os eleitores devem punir os políticos que, por oportunismo, se distanciem da política fiscal ótima. Note que a evidência de que $\gamma_{2}>0$ indicaria que a ausência de um controle político adequado contribui para o surgimento e intensificação dos ciclos eleitorais. Por fim, espera-se que $\gamma_{3} \geq 0$, já que eleitores racionais devem procurar reeleger os políticos mais competentes.

\section{DETERMINANTES POLÍTICOS DO COMPORTAMENTO FISCAL DOS ESTADOS}

Esta seção investiga os determinantes políticos e eleitorais do comportamento fiscal dos estados brasileiros durante o período 1986-2004. O objetivo principal é testar a existência de ciclos eleitorais na execução orçamentária dos estados. Uma preocupação adicional reside na obtenção de estimativas robustas, já que os resultados gerados nesta seção serão utilizados em análises subsequentes.

O modelo a ser estimado é idêntico ao especificado em (3). Todas as variáveis consideradas na presente análise caracterizam-se pelo fato de não se inserirem sob a esfera de controle ou interferência direta dos governadores estaduais (e.g., PIB nacional, mudanças legislativas federais). 0 intuito é o de viabilizar, em etapa posterior do trabalho, a identificação adequada das parcelas dos ciclos devidas ao oportunismo e à competência dos governantes.

O ciclo eleitoral é caracterizado por um conjunto de três dummies: uma para o ano pré-eleitoral (preelect), uma para o ano eleitoral (elect) e outra para o ano pós-eleitoral (postelect). 0 uso conjunto destas dummies permite especificar, de forma genérica, o ciclo eleitoral em toda a sua extensão.

A variável $E R$, por sua vez, busca captar os efeitos da Emenda da Reeleição (Emenda Constitucional 16/1997) sobre os ciclos eleitorais. Ela assume valor igual a 1, caso o governante tenha se candidatado à reeleição. Meneguin e Bugarin (2001) argumentaram que a possibilidade de reeleição incentivaria os governantes a não se endividarem excessivamente, já que eles próprios arcariam com os custos da dívida na hipótese de serem reeleitos. Entretanto, trabalhos recentes têm mostrado que, contrariamente à hipótese sugerida, a Reeleição estimulou a atividade manipuladora dos governantes, elevando a magnitude dos ciclos oportunistas. ${ }^{8}$

Para captar o componente estrutural presente nas variáveis orçamentárias, os modelos incluem uma tendência determinística (trend). Além disso, criou-se uma variável, denominada trendpol, visando capturar uma possível tendência na amplitude dos ciclos eleitorais ao longo do tempo. Esta variável assume valor igual a 1 para 1986, 2 para 1990, 3 para 1994, 4 para 1998, 5 para 2002 e zero para os demais anos, nos quais não se realizaram eleições. A justificativa teórica para a inclusão desta variável reside no fato de que o aprendizado e a experiência adquirida em sucessivas eleições contribuem para elevar o nível de monitoramento político, assim reduzindo a intensidade dos ciclos. Este argumento é utilizado por Brender e Drazen (2005) para explicar a constatação de que as manipulações fiscais são mais significativas em democracias jovens. A expectativa, portanto, é a de que as estimativas para a variável trendpol apresentem sinal negativo, indicando uma redução na amplitude do ciclo eleitoral ao longo do tempo.

Considerou-se, ainda, a presença de não-linearidades nas tendências acima descritas, adicionandose aos modelos o quadrado das variáveis trend e trendpol, denotadas, respectivamente, por trend2 e trendpol2. A finalidade é captar uma possível suavização na evolução destas tendências ao longo do tempo.

${ }^{8}$ Ver Nakaguma e Bender (2006) para resultados neste sentido. 
Por fim, incluíram-se como variáveis de controle: a taxa de crescimento do PIB nacional, a taxa de inflação e duas dummies para capturar a influência do Programa de Refinanciamento (Lei 9.496/97) e da Lei de Responsabilidade Fiscal (Lei Complementar 101/00) sobre as finanças públicas estaduais. Adicionalmente, foram consideradas: uma variável de ideologia partidária que identifica se o governo é de esquerda, ${ }^{9}$ uma medida de fragmentação das preferências do eleitorado ${ }^{10}$ e uma variável que captura o fato do governante pertencer, ou não, ao mesmo partido que o Presidente da República.

Os modelos foram estimados utilizando o método proposto por Blundell e Bond (1998a), também conhecido como estimador system-GMM para painéis dinâmicos. Este estimador utiliza eficientemente as condições de momento disponíveis e é o mais adequado quando as séries exibem elevado grau de persistência. ${ }^{11}$ As estimativas reportadas incluem resultados para os testes de especificação do modelo (Hansen-J) e de correlação serial no termo-aleatório (m2). Todos os modelos foram estimados com a variável dependente em especificação logarítmica, implicando em que os coeficientes devam ser interpretados em termos percentuais.

Os dados referentes à execução orçamentária dos estados foram obtidos no site da Secretaria do Tesouro Nacional do Ministério da Fazenda (http: //www.stn.fazenda.gov.br). As informações relativas aos resultados eleitorais e à estrutura político-partidária brasileira foram obtidas no site do Laboratório de Estudos Experimentais (LEEX) do Instituto Universitário de Pesquisas do Rio de Janeiro da Universidade do Rio de Janeiro (http://www.iuperj.br/leex). Todas as variáveis fiscais foram deflacionadas e ajustadas em termos per capita.

Os resultados são apresentados na Tabela $1 .^{12}$ As estimativas evidenciam a presença de ciclos políticos bem definidos, tanto nas receitas quanto nas despesas orçamentárias, caracterizados por fortes elevações durante os anos eleitorais e quedas acentuadas durante os anos pós-eleitorais.

Com exceção da despesa de capital, todas as demais variáveis se elevam significativamente durante o ano eleitoral. No período pós-eleitoral, foram observadas reduções significativas nas receitas e nas despesas de capital, em $60 \%$ e $28 \%$, respectivamente, evidenciando a ocorrência de ajustes fiscais cíclicos nestes períodos. A despesa de custeio, por outro lado, permanece $7 \%$ acima da média, fato que poderia ser atribuído às restrições legais inerentes ao regime de funcionalismo público, que dificultariam uma diminuição mais rápida dos gastos nesta categoria.

Os resultados relativos à Emenda da Reeleição indicam que a nova lei introduziu um estímulo adicional para as manipulações eleitoreiras. No lado das receitas, as estimativas apontam que ela implicou em um aumento na amplitude dos ciclos na receita total (27\%), na receita corrente (14\%) e nas transferências correntes (22\%). No lado das despesas, os resultados indicam que governantes candidatos à reeleição elevam a despesa total (29\%), a despesa corrente $(21 \%)$ e as despesas de custeio $(47 \%)$ acima dos demais governantes (não-candidatos à reeleição). Estes resultados parecem fazer bastante sentido, principalmente, quando se consideram as características das instituições políticas e eleitorais brasileiras. A falta de um maior grau de transparência política e a inexperiência do eleitorado, entre outros aspectos, criam elevados incentivos para que os governantes se distanciem das políticas socialmente ótimas.

Por fim, foi verificada uma tendência de decréscimo na magnitude dos ciclos ao longo do tempo, em resultado compatível com Brender e Drazen (2005). ${ }^{13}$ Os resultados também indicam a presença de uma não-linearidade nesta tendência, o que se observa pelo fato de que $\widehat{\beta}_{\text {trendpol } 2}>0$ e $\widehat{\beta}_{\text {trendpol }}<0$

\footnotetext{
${ }^{9}$ Foram considerados como partidos de esquerda: PDT, PTB, PSB, PSL e PT.

${ }^{10}$ Este índice mede a probabilidade de que dois eleitores aleatoriamente escolhidos tenham votados em candidatos diferentes. Esta medida é dada por: $F=1-\sum_{i} v_{i}$, onde $v_{i}$ é a fração dos votos obtida por cada concorrente.

${ }^{11}$ Ver Blundell e Bond (1998b) e Bond et alii (2002) para uma discussão intuitiva sobre o assunto.

${ }^{12}$ Os resultados para as variáveis de controle foram omitidos por uma questão de espaço. Para mais detalhes, ver Cossío (2000), Bittencourt e Hillbrecht (2003), Rocha e Giuberti (2004) e Nakaguma (2006).

${ }^{13} \mathrm{~A}$ única exceção se refere à despesa de capital, cujos ciclos não apresentam auge nos anos eleitorais.
} 


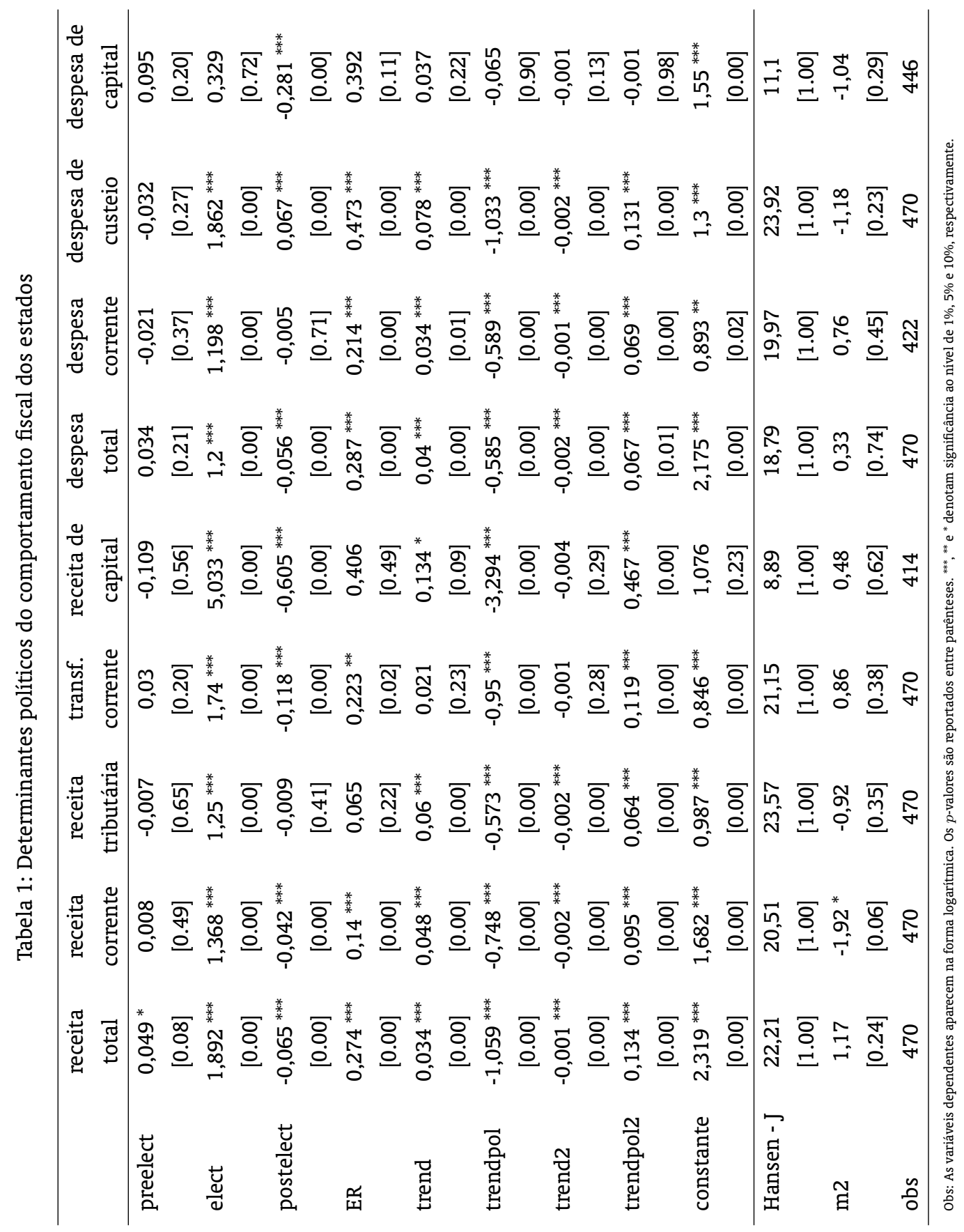


(ambos significantes) para a maioria das séries, ou seja, a magnitude dos ciclos diminui a taxas decrescentes. Os ciclos para a despesa total são ilustrados na Figura $1 .{ }^{14}$

Figura 1: Ciclos eleitorais nos estados: Despesa total

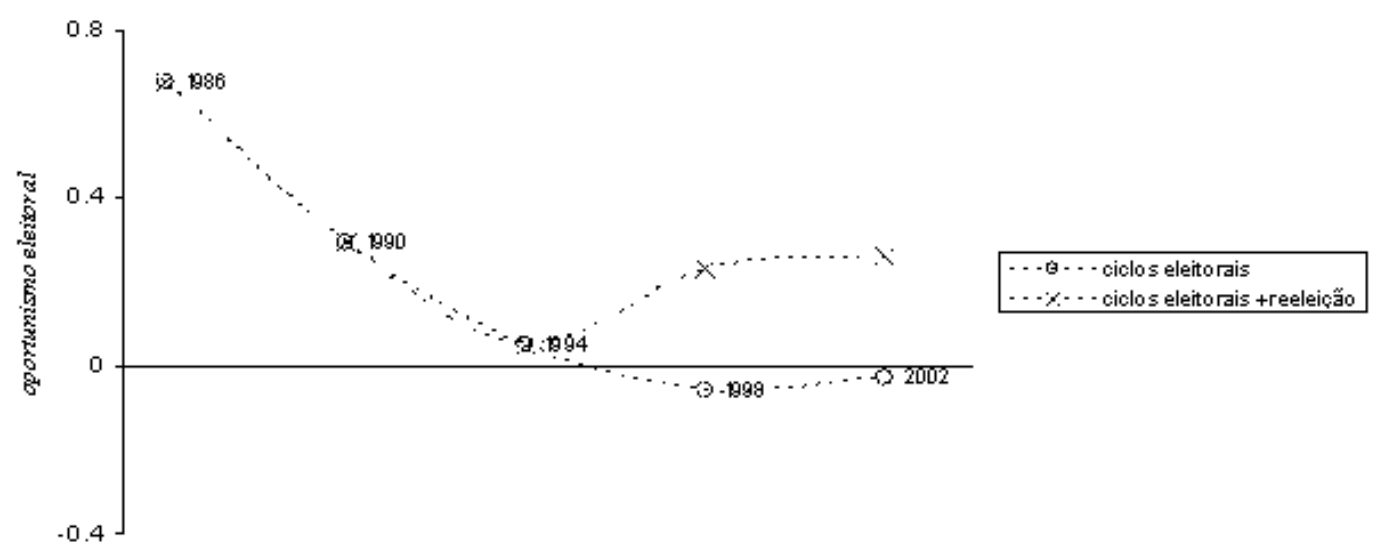

\section{COMPORTAMENTO DO ELEITORADO}

Esta seção analisa o comportamento do eleitorado em relação à política fiscal implementada pelos governos durante os anos eleitorais. $O$ objetivo principal consiste em investigar as causas determinantes da existência de ciclos na política fiscal dos estados brasileiros. As explicações levantadas pelos modelos de ciclos políticos e controle eleitoral são testadas empiricamente, objetivando determinar-se qual desses efeitos tem prevalecido no Brasil.

\subsection{Metodologia}

Na seção anterior, o seguinte modelo foi estimado:

$$
y_{i t}=z_{i t}^{\prime} \cdot \pi+\delta_{1} \cdot \text { elect }_{i t}+\delta_{2} \cdot E R_{i t}+\delta_{3} \cdot \text { trendpol }_{i t}+\delta_{4} \cdot \text { trendpol }_{i t}+a_{i}+v_{i t},
$$

onde, por simplicidade, está-se a considerar a regressão apenas em anos eleitorais. Observados sob o ponto de vista do eleitorado, os resultados fiscais podem ser divididos em três principais componentes:

(1) uma parcela esperada, $\widetilde{y}_{i t}=z_{i t}^{\prime} \cdot \widehat{\pi}+\widehat{a}_{i}$, função de variáveis sobre as quais os governantes não possuem qualquer poder de influência;

(2) uma parcela esperada e devida exclusivamente ao fato de estar-se em um ano eleitoral, $\widehat{\delta}_{1}$. elect $t_{i t}+$ $\widehat{\delta}_{2} \cdot E R_{i t}+\widehat{\delta}_{3} \cdot$ trendpol $_{i t}+\widehat{\delta}_{4} \cdot$ trendpol $2_{i t} ; \mathrm{e}$

(3) uma parcela residual, $\widehat{v}_{i t}$, não explicada pelas variáveis do modelo.

\footnotetext{
${ }^{14}$ Note que o efeito das eleições sobre as variáveis fiscais deve ser obtido através da seguinte operação: $\beta_{\text {elect }}+\beta_{\text {trendpol }} \times$ trendpol $_{i t}+\beta_{\text {trendpol } 2} \times$ trendpol $_{i t}$.
} 
O método proposto consiste em decompor os ciclos eleitorais, utilizando a parcela esperada dos ciclos, $\widehat{\delta}_{1} \cdot$ elect $_{i t}+\widehat{\delta}_{2} \cdot E R_{i t}+\widehat{\delta}_{3} \cdot$ trendpol $_{i t}+\widehat{\delta}_{4} \cdot$ trendpol $2_{i t}$, como uma proxie para o nível de oportunismo, e o resíduo obtido nos anos eleitorais, $\widehat{v}_{i t}$, como uma proxie para a competência dos governantes. Na linha dos modelos de sinalização, a justificativa para este procedimento está em que, em um "equilíbrio separador", somente a parcela não-esperada dos ciclos pode conter alguma informação sobre o nível de competência dos governantes. ${ }^{15}$

A validade desta metodologia requer a hipótese de que, para uma dada eleição, todos os governantes apresentem um mesmo nível intrínseco de oportunismo, independentemente do fato de serem, ou não, competentes. Trata-se de uma hipótese que se faz necessária, pois tanto oportunismo quanto competência são características não-observáveis, nem claramente distinguíveis entre si. De qualquer forma, é razoável assumir que o estímulo para o comportamento oportunista difira apenas em função do contexto político-institucional vigente em um determinado estado e/ou período de tempo, cujos aspectos e características básicas podem ser controlados através das variáveis políticas e tendências consideradas nas regressões acima. Neste sentido, pode-se dizer que a metodologia proposta neste trabalho é suficientemente flexível, sendo consistente com diversas especificações e formas funcionais para o sistema formado pelas equações (3) e (4).

\subsection{Modelo econométrico}

O modelo a ser estimado nesta seção é dado por:

$$
\text { voto }_{i t}=\gamma_{1} . \Delta \% \widetilde{y}_{i t}+\gamma_{2} . \text { oportunismo } i t+\gamma_{3} . \text { competência }_{i t}+\omega_{i t}^{\prime} \cdot \pi+\eta_{i}+\varepsilon_{i t},
$$

onde $\Delta \% \widetilde{y}_{i t}=\frac{\left(\widetilde{y}_{i t}-\widetilde{y}_{i t-1}\right)}{\widetilde{y}_{i t-1}}$ é a variação percentual do resultado fiscal previsto no ano eleitoral, oportunismo $_{i t}$ é a parcela esperada dos ciclos eleitorais, competência $a_{i t}$ é o componente não-esperado dos ciclos, $\omega_{i t}$ representa um conjunto de variáveis de controle, $\eta_{i}$ é um efeito-fixo estadual e $\varepsilon_{i t}$ é um termo aleatório $i i d$.

A variável voto $_{i t}$ consiste no percentual de votos obtidos em primeiro turno pelo candidato do governo. Um aspecto a ser ressaltado é o de que o presente estudo baseia-se na manutenção dos partidos e não na reeleição dos governantes propriamente dita - uma vez que esta possibilidade passou a vigorar somente a partir de $1997 .{ }^{16}$ Uma possível dificuldade com este procedimento é o de que, em geral, os governantes não se preocupam com os seus sucessores da mesma maneira que se preocupam consigo mesmos. A Emenda da Reeleição, neste sentido, constituiu-se em um importante fator de mudança institucional, estabelecendo uma nova dinâmica nas disputas eleitorais. A idéia é a de que os candidatos à reeleição entram nas disputas em condições mais favoráveis, por possuírem maior visibilidade e terem a "máquina administrativa" às suas disposições. Uma análise preliminar dos dados confirma esta intuição. A Tabela 2 reporta o percentual de votos obtivos em primeiro turno pelos candidatos apoiados pelos governos de cada estado. ${ }^{17}$ Note que nas eleições de 1998 e 2002 o percentual de partidos que se mantiveram no poder ( $55,6 \%$ e $51,9 \%$, respectivemente) é significativamente maior do que nas eleições anteriores (34,8\% em 1990 e 48,1\% em 1994). Neste sentido, é importante considerar nas regressões a entrada em vigor da Emenda da Reeleição a partir de 1997.

\footnotetext{
${ }^{15}$ Ver Wolfers (2007) para uma abordagem semelhante.

${ }^{16}$ A maioria dos trabalhos adotam este mesmo procedimento. Ver, por exemplo, Libanio e Menezes-Filho (2003), Sakurai (2005) e Sakurai e Menezes-Filho (2008).

${ }^{17}$ Por exemplo, o candidato apoiado pelo governo de Tasso Jereissati (PSDB/CE) nas eleições de 1998 recebeu $62.7 \%$ dos votos em primeiro turno. No caso, o próprio Tasso Jereissati, candidato à reeleição naquele pleito, foi reeleito em primeiro turno, mantendo o PSDB no governo do Ceará por mais um mandato $(M P=1)$. De maneira semelhante, o candidato apoiado pelo governo de Cristovam Buarque (PT/DF) nas eleições de 1998 recebeu $42.7 \%$ dos votos em primeiro turno. No caso, o próprio Cristovam Buarque, candidato à reeleição naquele pleito, não foi reeleito ao governo do Distrito Federal $(M P=0)$, sendo substituído por Joaquim Roriz (PMDB).
} 


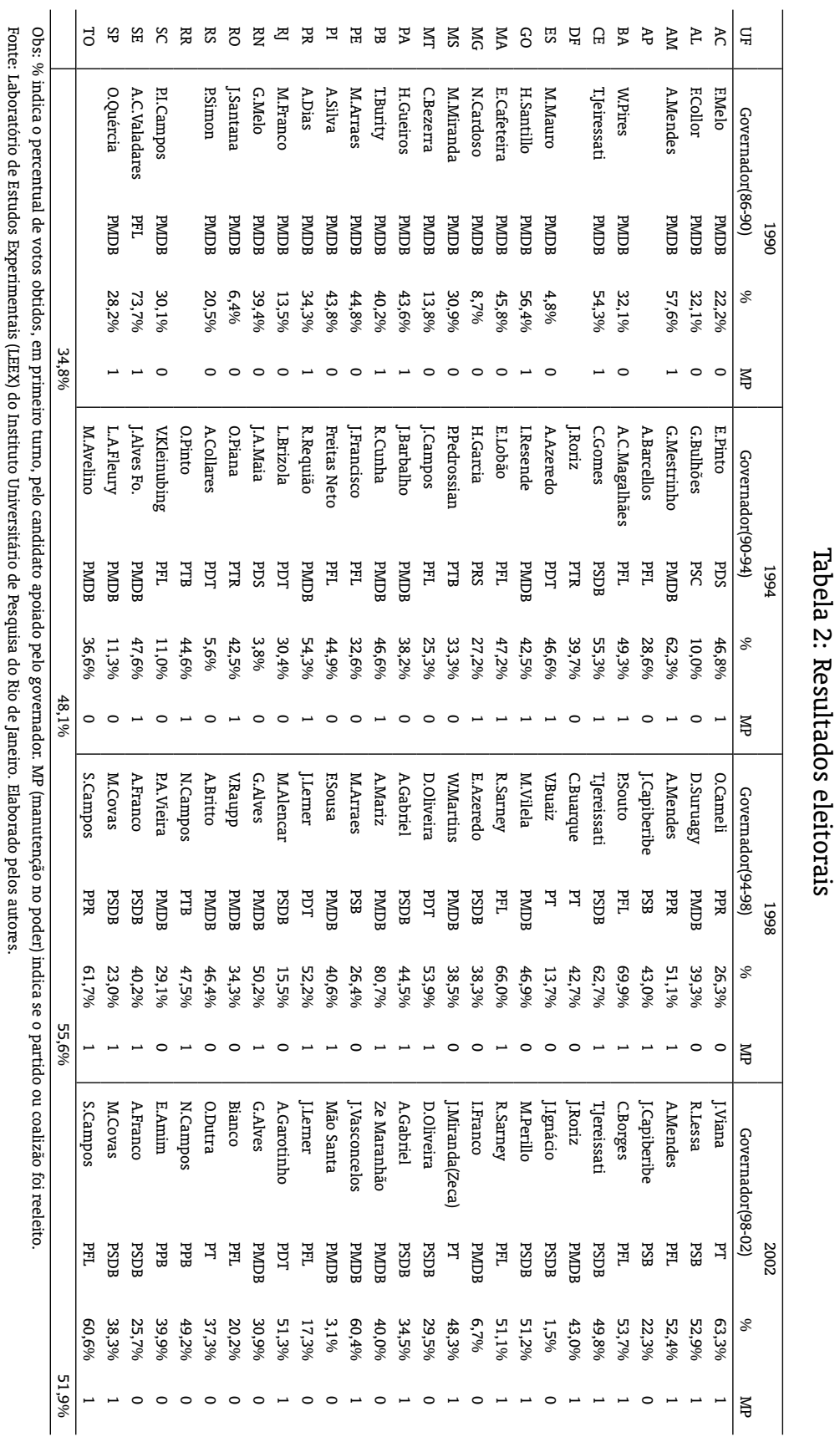


Duas outras variáveis político-partidárias foram adicionadas como controle. Em primeiro lugar, considerou-se a inclusão de um índice de fragmentação das preferências (fragpref) com o intuito de capturar o ambiente político vigente nos estados. Além disso, incluiu-se uma variável indicando se o candidato pertence ou não ao partido do Presidente da República (partpres). Uma primeira intuição indicaria que a circunstância de estar-se filiado ao partido do Presidente facilitaria a reeleição dos governantes. Por outro lado, a literatura na área de economia política ressalta a existência de um natural desgaste na popularidade presidencial ao longo de seu mandato, o que poderia prejudicar a performance dos candidatos ligados a ele.

Por fim, foram adicionados diversos indicadores para o desempenho econômico nos anos eleitorais: o crescimento do PIB estadual, o crescimento do PIB nacional e a taxa de inflação. Também foi considerada a inclusão da diferença entre as taxas de crescimento do produto estadual e nacional, com o intuito de testar se os eleitores avaliam os governantes com base na performance econômica relativa, em consonância com os modelos de "yardstick competition". ${ }^{18}$ Entretanto, nenhuma dessas variáveis apresentou significância estatística e, por este motivo, foram excluídas dos modelos.

\subsection{Resultados}

Esta subseção reporta os resultados obtidos para os determinantes políticos e econômicos do voto nas eleições estaduais brasileiras. A amostra utilizada abrange as eleições realizadas entre 1990 e 2002. A Tabela 3 reporta regressões com a variável dependente voto $_{i t}$, estimadas via metodologia de painel com a presença de efeitos-fixos estaduais e dummies para os anos de 1994, 1998 e $2002 .{ }^{19}$ observe que a variável oportunismo mostrou-se significante em todos os casos, evidenciando que os eleitores respondem positivamente aos ciclos oportunistas nas variáveis fiscais. Estes resultados demonstram que os ciclos eleitorais estão sendo induzidos, ao menos em parte, pela falta de um controle político adequado por parte do eleitorado. A parcela de competência dos ciclos, por outro lado, mostrou-se marginalmente significante apenas nos casos das receitas total e corrente, enquanto que a parcela prevista das variações fiscais mostrou-se insignificante em todas as regressões.

Para verificar a robustez e consistência desses resultados, a Tabela 4 reporta regressões com a variável dependente manutenção no poder $(M P)$ - uma dummy indicando se o partido do governo foi ou não reeleito. Os modelos são estimados via logit com efeitos-fixos estaduais e dummies para os anos de 1994, 1998 e 2002. Os resultados obtidos confirmam o fato de que os eleitores brasileiros recompensam fortemente a parcela oportunista dos ciclos eleitorais.

Embora as dummies de ano consideradas nas regressões acima capturem, ao menos parcialmente, o impacto da entrada em vigor da "Emenda da Reeleição", fica a dúvida se os resultados obtidos são robustos a especificações alternativas do modelo. Uma possível abordagem poderia consistir na inclusão da variável $E R$ diretamente nas regressões. Entretranto, esta alternativa mostrou-se inviável devido à existência de uma elevada correlação entre $E R$ e oportunismo, especialmente nos anos finais da amostra. ${ }^{20}$ Desta forma, decidiu-se por repartir a amostra em dois períodos (1990-1994 e 1998-2002), com o intuito de capturar as alterações institucionais induzidas pela Emenda da Reeleição, bem como possíveis modificações no padrão de comportamento dos eleitores. Os modelos foram estimados por mínimos quadrados ordinários $(O L S)$, tendo em vista que os testes realizados rejeitaram a significância

\footnotetext{
${ }^{18}$ Ver Besley e Case (1995a) e Wolfers (2007).

${ }^{19}$ Note que a introdução de "regressores gerados" nos modelos implica em que os erros-padrão obtidos subestimam o seu verdadeiro valor. Isso ocorre porque estas estimativas não incorporam a incerteza associada à estimação de primeiro-estágio. Este viés pode ser corrigido analiticamente ou por meio de métodos de re-amostragem, como o bootstrap. O presente trabalho não aplica nenhuma destas correções. No entanto, a expectativa é a de que esta omissão não altere os resultados de forma significativa, assim como em Wolfers (2007).

${ }^{20}$ Note que, por definição, oportunismo $i t=\widehat{\delta}_{1}$.elect ${ }_{i t}+\widehat{\delta}_{2} E R_{i t}+\widehat{\delta}_{3}$ trendpol $_{i t}+\widehat{\delta}_{4}$ trendpol $2_{i t}$.
} 


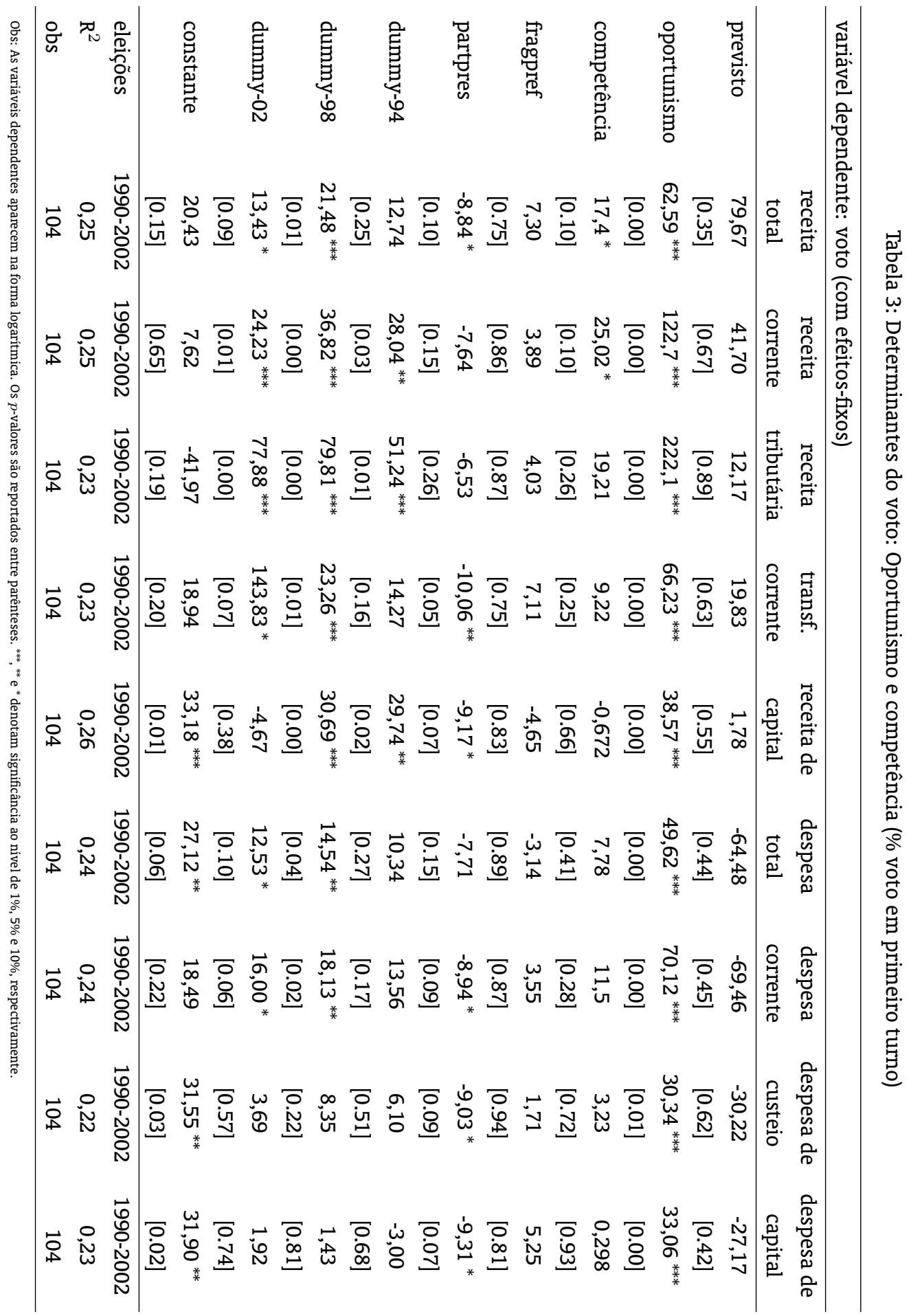




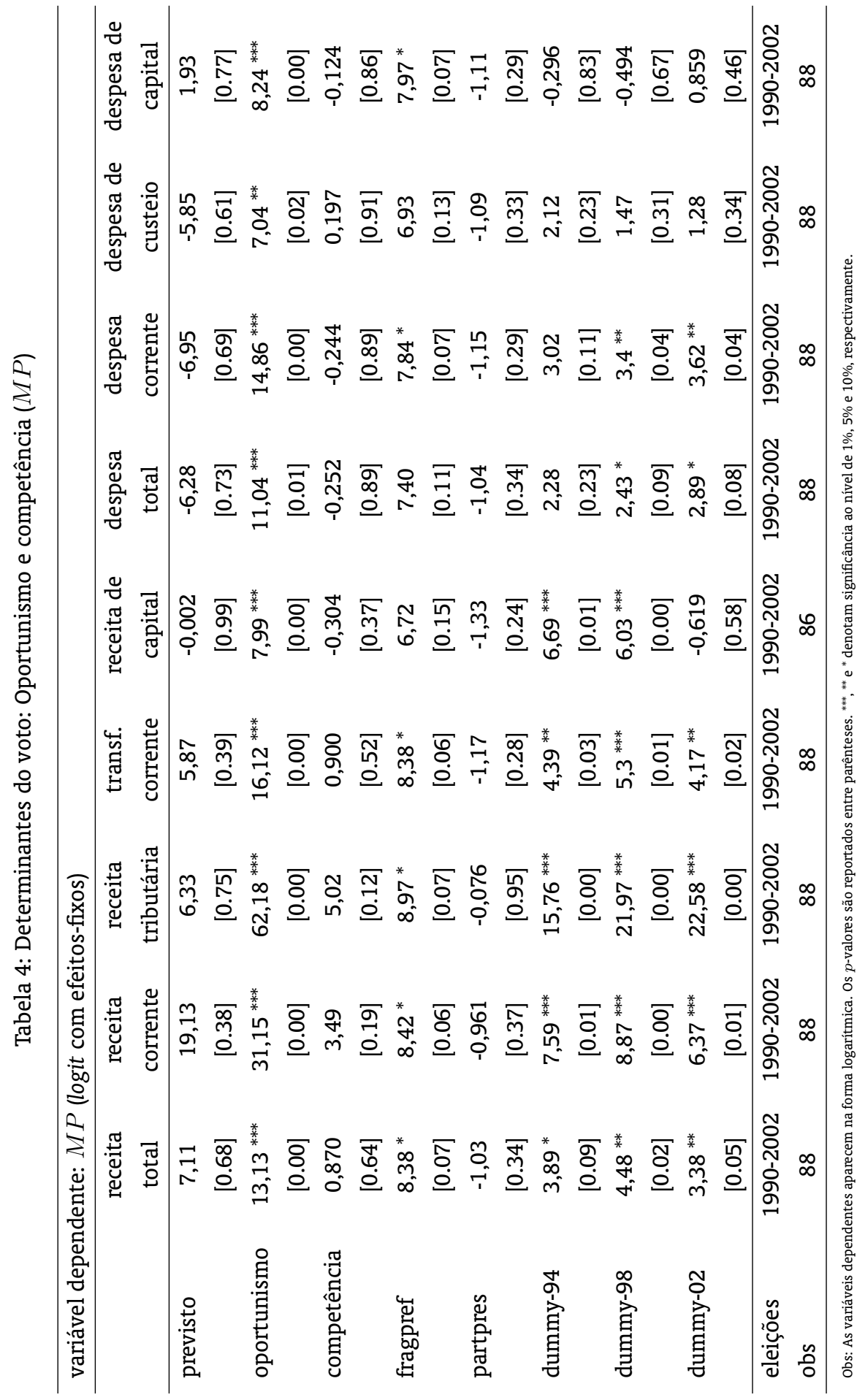


dos efeitos-fixos estaduais. A Tabela 5 reporta os resultados obtidos para as variáveis da receita orçamentária, considerando a partição proposta para a amostra e utilizando a variável dependente $v o t o_{i t}$.

Note que a parcela oportunista dos ciclos mostrou-se significante na maioria das regressões, corroborando, mais uma vez, a idéia de que os ciclos eleitorais estão sendo induzidos pela falta de um monitoramento político adequado por parte dos eleitores. Esta observação, no entanto, deve ser qualificada pela existência de uma tendência declinante na magnitude do coeficiente da variável oportunismo, visto que, em geral, $\widehat{\gamma}_{\text {oport }}^{90-94}>\widehat{\gamma}_{\text {oport }}^{98-02}$. Este fato indica que o efeito dos ciclos oportunistas sobre as chances de reeleição tem diminuído ao longo do tempo, evidenciando uma evolução na capacidade do eleitor de identificar e punir manipulações eleitoreiras.

A variável competência, por outro lado, mostrou-se significante apenas na parcela final da amostra, demonstrando uma possível evolução na capacidade dos eleitores de reconhecer a atividade sinalizadora dos governantes. Ceteris paribus, os governantes que conseguem "surpreender" os eleitores com um maior volume de receitas total, corrente e tributária e transferências correntes são recompensados com uma maior margem de votos. Note que o "choque de competência" na receita de capital não é remunerado pelos eleitores, em um resultado compatível com a percepção de que o endividamento é prejudicial para a sustentabilidade das finanças públicas estaduais.

Com relação à parcela prevista dos ciclos, foram obtidos três resultados incompatíveis com o princípio de racionalidade dos agentes. Em primeiro lugar, os eleitores parecem punir a elevação da receita tributária, ainda que ela se deva a causas completamente fora do controle dos governantes. A elevação esperada das transferências correntes e das receitas de capital, por outro lado, parecem ser bem vistas pelos eleitores.

A Tabela 6 apresenta os resultados para as variáveis da despesa orçamentária. De forma semelhante ao obtido anteriormente, a variável oportunismo mostrou-se significante na maioria das regressões, com o seu coeficiente apresentando uma nítida tendência de queda ao longo do tempo. Neste sentido, as conclusões que se seguem são idênticas às anteriores, a saber: (1) a falta de um controle político adequado tem induzido a produção de ciclos nas despesas orçamentárias; e (2) o nível de controle político tem se elevado ao longo do tempo.

A variável competência, por outro lado, não se mostrou significante em nenhuma das regressões. ${ }^{21}$ Uma possível explicação para este resultado pode ser atribuída ao fato de que a avaliação da competência dos governantes com base nos gastos realizados é altamente subjetiva. De fato, o montante total de recursos despendidos consiste em apenas uma, dentre diversas outras variáveis a serem consideradas. Critérios como a alocação eficiente dos recursos e a resolução de questões distributivas são igualmente importantes e desempenham um papel relevante sobre a percepção dos eleitores. Já a avaliação da competência com base na eficiência arrecadatória pode ser considerada como mais direta e objetiva, sendo razoável entender-se que, ceteris paribus, quanto maior a arrecadação obtida, maior o grau de competência de um governante.

Com relação às variáveis de controle, duas observações são devidas e aplicáveis aos resultados referentes tanto às receitas quanto às despesas orçamentárias. Em primeiro lugar, deve-se observar que a magnitude (em termos absolutos) dos coeficientes estimados para a variável fragpref aumentou consistentemente ao longo do tempo, demonstrando que as eleições mais recentes têm se tornando cada vez mais disputadas. Além disso, deve-se notar que a variável partpres apresentou-se significante, e com um sinal negativo, apenas nos períodos iniciais da amostra. Uma possível explicação para este resultado poderia ser atribuída ao fato de que as primeiras eleições foram realizadas em um período de transição democrática, durante a vigência de um intenso processo de fragmentação do sistema político-partidário, o que poderia ter dificultado a manutenção do partido do Presidente no poder.

Por fim, é interessante notar que a receita de capital e a despesa de custeio foram as únicas variáveis cujas manipulações oportunistas na parcela final da amostra não demonstraram afetar, de forma sig-

\footnotetext{
${ }^{21}$ Exceção feita ao caso da despesa de capital, em que a variável competência apareceu com sinal negativo e significante na primeira parcela da amostra.
} 


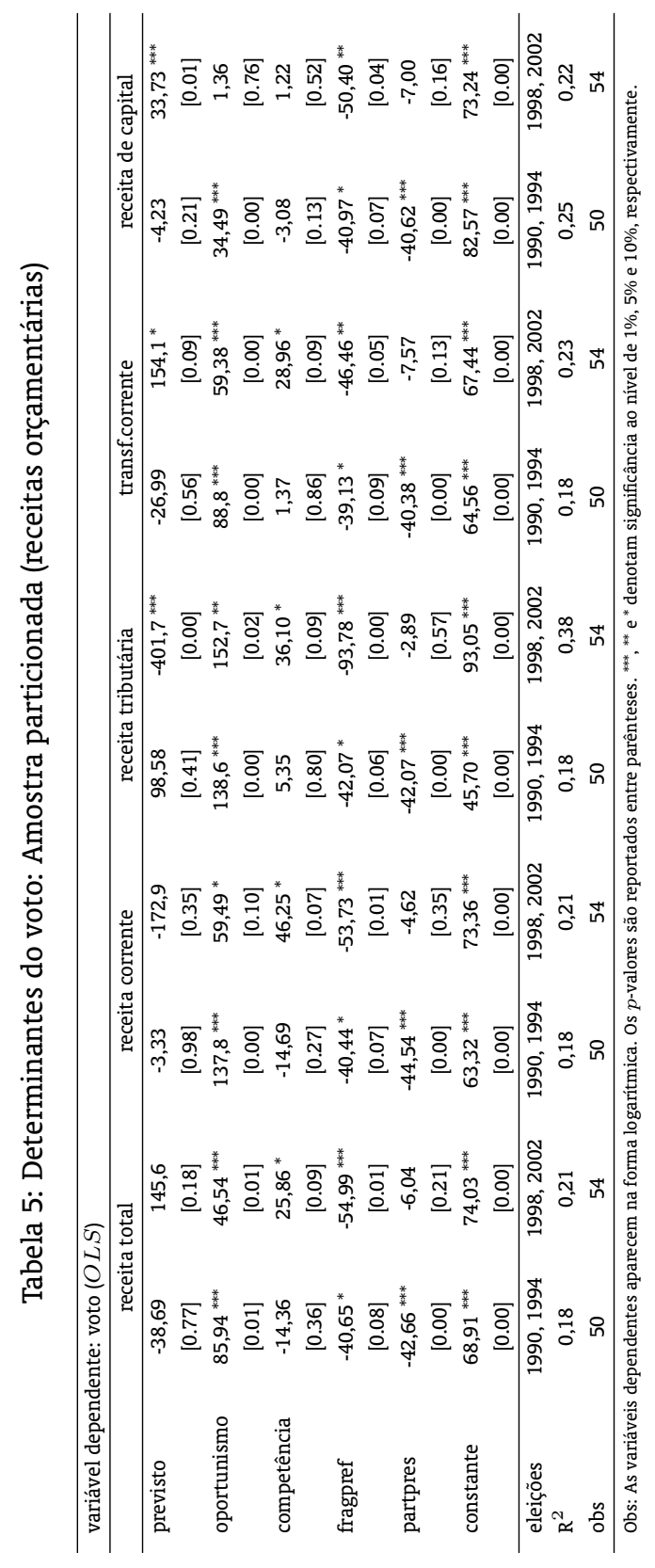




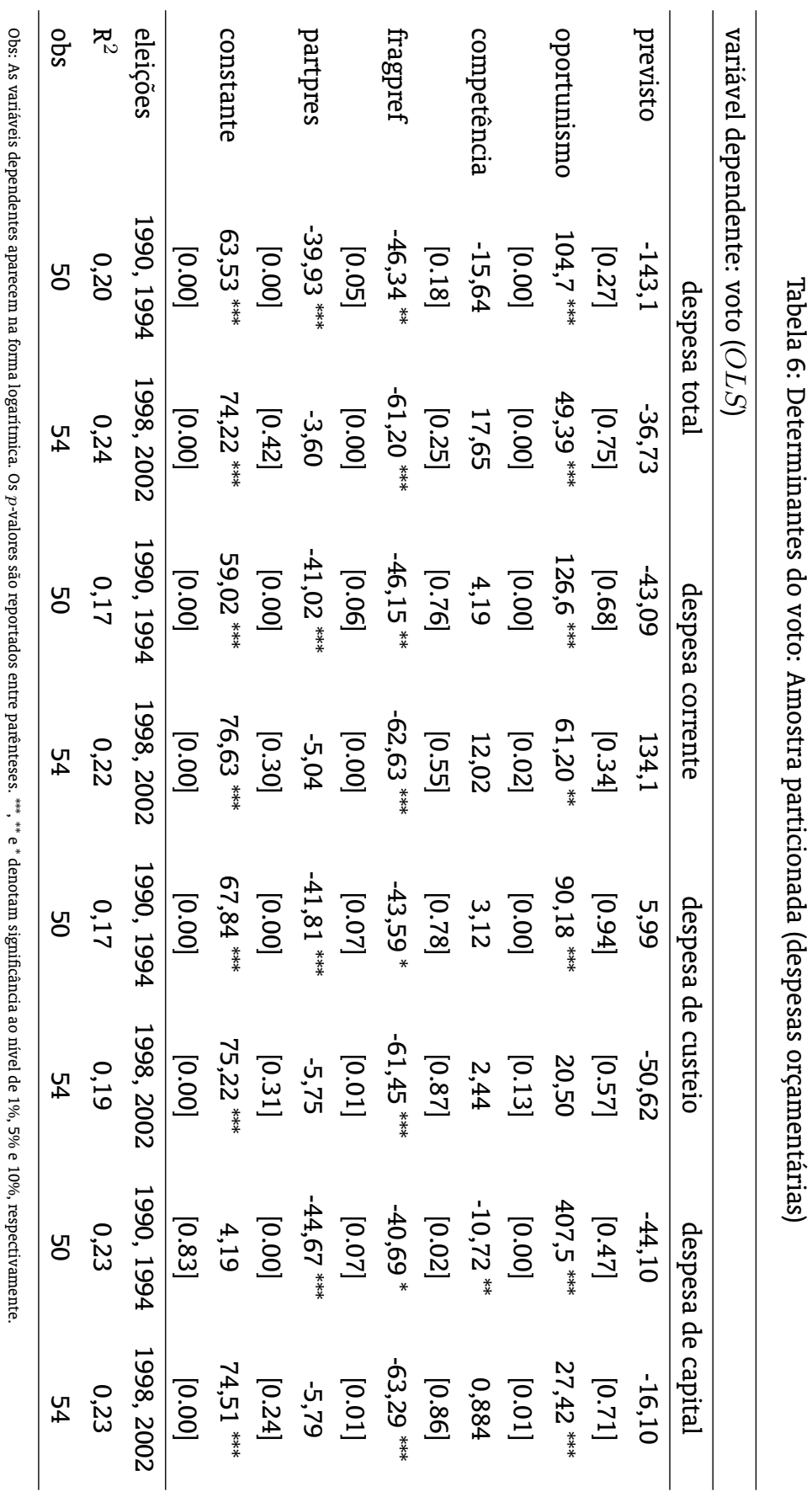


nificante, as chances de reeleição dos governantes. Estes resultados são compatíveis com a percepção geral, recentemente reforçada pela entrada em vigência da Lei de Responsabilidade Fiscal, de que o endividamento e a elevação dos gastos com funcionalismo são prejudiciais para o equilíbrio das finanças estaduais.

\subsection{Transparência política}

Por fim, esta subseção procura investigar se o nível de controle político exercido pelos eleitores varia conforme o ambiente político-institucional vigente nos estados. Com este intuito, foram adicionados aos modelos interações da variável oportunismo com diversas proxies para o grau de transparência política regional. A finalidade é testar se os eleitores são mais aptos para identificar e punir manipulações oportunistas nos estados mais transparentes, isto é, $\gamma_{\text {oportunismo }} \times$ transparência $<0$. As proxies utilizadas foram as seguintes: (1) mídia ${ }_{i}$ : número de estações de rádio por cem mil habitantes no estado $i$; (2) comput $_{i}$ : percentual de domicílios com computador pessoal; (3) internet ${ }_{i}$ : percentual de domicílios com acesso à internet; (04) alfabet $_{i}$ : percentual de habitantes alfabetizados; e (5) urbano ${ }_{i}$ : percentual de habitantes residentes no setor urbano. ${ }^{22}$

Os resultados obtidos com estas diversas proxies mostraram-se bastante semelhantes entre si e, assim sendo, decidiu-se por reportar apenas as regressões estimadas com a variável comput ${ }_{i}$. As Tabelas 7 e 8 apresentam os resultados para a receita e despesa orçamentárias, respectivamente. Para o período inicial da amostra, as estimativas indicam que quanto maior o grau de transparência política, menor o impacto das manipulações oportunistas sobre as chances de reeleição dos governantes. Esta constatação indica que a presença de um ambiente institucional favorável permite o exercício de um controle mais rigoroso sobre o comportamento dos políticos. Para o período final da amostra, por outro lado, a variável de transparência não se mostrou significante, o que pode ser visto como um indício de que o nível de controle político nos estados convergiu para um mesmo padrão, eliminando as diferenças anteriormente observadas.

\section{CONCLUSÃO}

O presente trabalho teve como principal objetivo investigar as causas determinantes da existência de ciclos eleitorais na política fiscal dos estados brasileiros. Em termos metodológicos, a sua principal contribuição consiste em propor um novo método para analisar o impacto dos ciclos políticos sobre a performance eleitoral dos governantes. A idéia principal consiste em reconhecer que os eleitores podem recompensar e/ou punir parcelas distintas de um mesmo ciclo político. Intuitivamente, por exemplo, a elevação dos gastos públicos pode ser vista tanto como benéfica (caso esteja associada à sinalização de competência) quanto como maléfica (caso esteja associada a uma situação de oportunismo eleitoral). Os resultados obtidos neste trabalho contradizem, de certa maneira, a literatura tradicional, que costuma documentar o fato de que os eleitores são intrinsecamente "conservadores".

De forma mais específica, este trabalho procurou abordar as seguintes principais questões: (1) Os ciclos eleitorais estão realmente presentes na política fiscal dos estados brasileiros?; e (2) Quais são as causas determinantes da existência destes ciclos no Brasil? E, em que medida poder-se-ia dizer que os eleitores são racionais, no sentido de serem capazes de distinguir as parcelas de oportunismo e de competência dos ciclos eleitorais?

Os resultados indicam a presença de ciclos políticos bem definidos, caracterizados por fortes elevações durante os anos eleitorais e quedas acentuadas durante os anos pós-eleitorais. Além disso, foi possível constatar que a magnitude dos ciclos eleitorais tem diminuído rapidamente ao longo do tempo, em um resultado compatível com o obtido por Brender e Drazen (2005), e que poderia ser atribuído ao

\footnotetext{
${ }^{22}$ Estes dados foram obtidos a partir da Pesquisa Nacional de Domicílios (PNAD) referente ao ano de 2003 e do Sistema Nacional de Indicadores Urbanos (SNIU).
} 


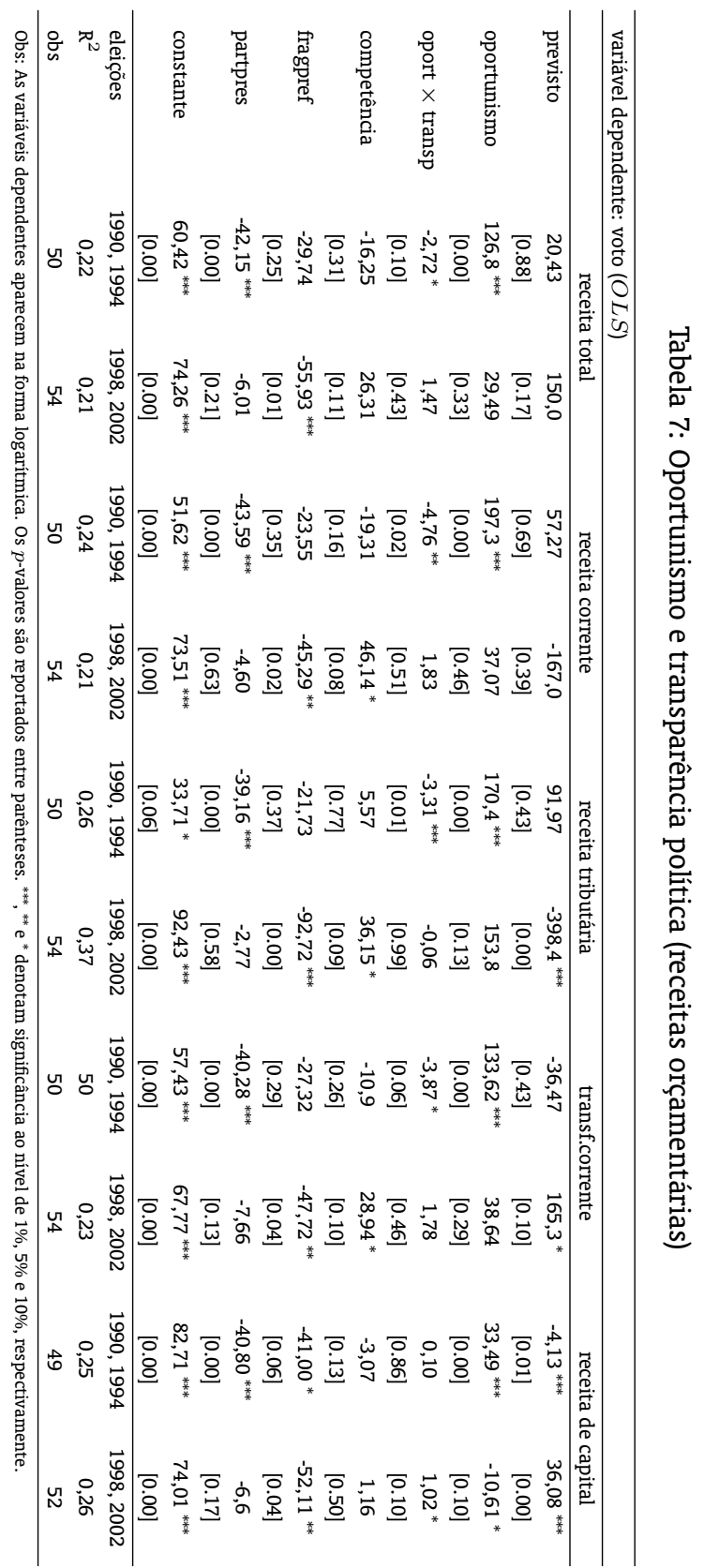




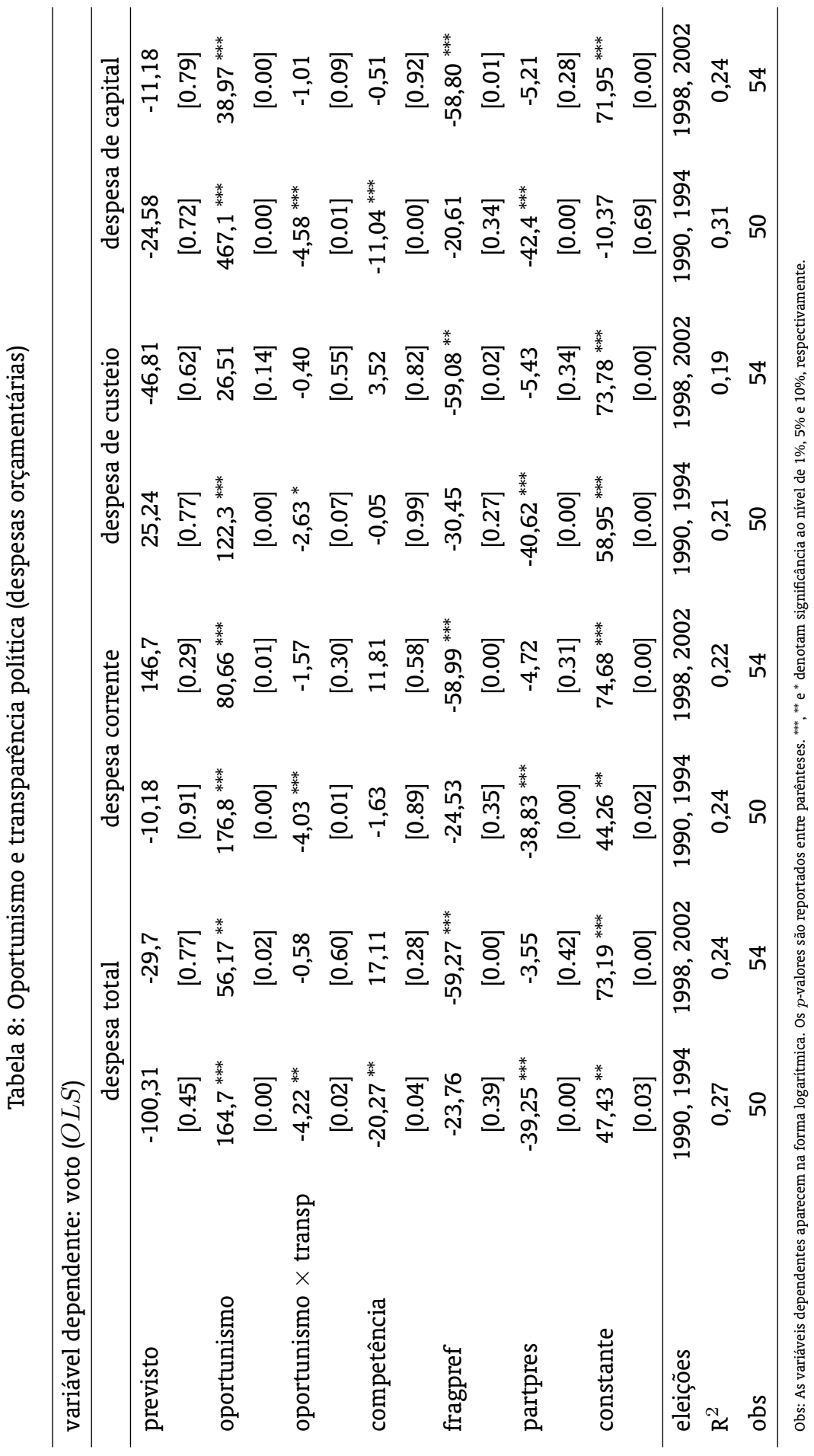


aprendizado e à experiência adquirida pelos eleitores ao longo das eleições, assim como à evolução das instituições fiscais e democráticas no país.

Com relação às causas determinantes da existência dos ciclos eleitorais, constatou-se que o eleitorado recompensa a parcela oportunista dos ciclos, tanto nas receitas quanto nas despesas orçamentárias. É neste sentido que se pode afirmar que os ciclos estão sendo induzidos, pelo menos em parte, pela falta de um controle político adequado por parte dos eleitores. Este resultado, no entanto, deve ser qualificado pela evidência de que o efeito do oportunismo sobre as chances de reeleição tem diminuído ao longo do tempo, indicando uma evolução na capacidade do eleitor de identificar e punir as manipulações eleitoreiras. Com relação à parcela de competência dos ciclos, os resultados apontaram que o processo de sinalização de competência se dá, principalmente, através das variáveis da receita orçamentária. Este resultado está de acordo com os modelos de ciclos políticos racionais e indica que a avaliação da competência com base na eficiência arrecadatória é mais objetiva do que a mesma avaliação baseada no montante de recursos despendidos.

Finalmente, este trabalho demonstrou a importância de levar-se em conta a estrutura evolutiva dos ciclos políticos e do comportamento do eleitorado ao longo do tempo. A dinâmica dos ciclos eleitorais foi capturada através da variável de tendência nos ciclos, trendpol, enquanto que a modificação do comportamento do eleitorado foi capturada através das partições realizada na amostra. Sob esta perspectiva, pode-se concluir que a evidência de conservadorismo fiscal é conciliável com a existência de ciclos eleitorais: (1) os ciclos existem nas "democracias jovens" e vão se reduzindo à medida que os eleitores adquirem experiência ao longo das eleições; (2) ao mesmo tempo, o nível de controle político se eleva e os eleitores passam a reconhecer e punir manipulações eleitoreiras, tornando-se, assim, "fiscalmente conservadores".

\section{BIBLIOGRAFIA}

Akhmedov, A. \& Zhuravskaya, E. (2004). Opportunistic political cycles: Test in young democracy setting. Quarterly Journal of Economics, 119(4):1301-1338.

Alesina, A. \& Perotti, R. (1995). The political economy of budget deficits. IMF Staff Papers, 1-37.

Alesina, A., Perotti, R., \& Tavares, J. (1998). The political economy of fiscal adjustments. Brooking Papers on Economic Activity, 1:197-248.

Alesina, A., Roubini, N., \& Cohen, G. (1997). Political Cycles and the Macroeconomy. The MIT Press, Cambridge, Massachussets.

Barro, R. (1979). On the determination of public debt. Journal of Political Economy, 87:940-971.

Besley, T. \& Case, A. (1995a). Does political accountability affect economic policy choices? Evidence from gubernatorial term limits. Quarterly Journal of Economics, 110:769-798.

Besley, T. \& Case, A. (1995b). Incumbent behavior: Vote-seeking, tax-setting and yardstick competition. American Economic Review, 85:25-45.

Bittencourt, J. L. \& Hillbrecht, R. (2003). Ciclo político na economia brasileira: Um teste para a execução orçamentária dos governos estaduais - 1983/2000. In Anais do XXXI Encontro Nacional de Economia, Porto Seguro. ANPEC.

Blundell, R. \& Bond, S. (1998a). GMM estimation with persistent panel data: An application to production functions. Mimeo.

Blundell, R. \& Bond, S. (1998b). Initial conditions and moment restrictions in dynamic panel data models. Journal of Econometrics, 87:115-143. 
Bond, M., Nauges, C., \& Windmeijer, F. (2002). Unit roots and identification in autoregressive panel data models: A comparison of alternative tests. Mimeo.

Brender, A. (2003). The effect of fiscal performance on local government election results in Israel: 19891998. Journal of Public Economics, 87:2187-2205.

Brender, A. \& Drazen, A. (2005). Political budget cycles in new versus established democracies. Journal of Monetary Economics, 52(7):1271-1295.

Brender, A. \& Drazen, A. (2008). How do budget deficits and economic growth affect reelection prospects? Evidence from a large cross-section of countries. American Economic Review, 98(5):2203-2220.

Cossío, F. A. B. (2000). Comportamento fiscal dos governos estaduais brasileiros: Determinantes políticos e efeitos sobre o bem estar dos seus estados. Dissertação de mestrado, UnB. Monografia agraciada com menção honrosa no V Prêmio de Monografia da Secretaria do Tesouro Nacional - Tópicos Especiais de Finanças Públicas (do site do Tesouro Nacional).

Drazen, A. (2000). Political Economy in Macroeconomics. Princeton University Press, Princeton, NJ.

Ferejohn, J. (1986). Incumbent performance and electoral control. Public Choice, 50:5-26.

Franzese, R. J. (2002). Electoral and partisan cycles in economic policies and outcomes. Annu. Rev. Polit. Sci., 5(X):369-421.

Kraemer, M. (1997). Electoral budget cycles in Latin America and Caribbean: Incidence, causes and political futility. Working Papers Series 354. Office of the chief Economist, BID.

Libanio, R. \& Menezes-Filho, N. (2003). Indicadores sociais e desempenho nas eleições estaduais. In Anais do XXXII Encontro Nacional de Economia, João Pessoa. ANPEC.

Mendes, M. J. (2004). Federalismo fiscal e crescimento do governo: Evidências eleitorais para o Brasil. In Anais do XXXII Encontro Nacional de Economia, João Pessoa. ANPEC.

Meneguin, F. B. \& Bugarin, M. S. (2001). Reeleição e política fiscal: Um estudo dos efeitos nos gastos públicos. Economia Aplicada, 5(3):600-22.

Nakaguma, M. Y. (2006). Ciclos políticos e resultados eleitorais: Um estudo sobre o comportamento do eleitor brasileiro. Dissertação de mestrado, Departamento de Economia, Universidade de São Paulo.

Nakaguma, M. Y. \& Bender, S. (2006). A emenda da reeleição e a lei de responsabilidade fiscal: Impactos sobre ciclos políticos e performance fiscal dos estados (1986-2002). Revista de Economia Aplicada, 10(3):377-397.

Olters, J. P. (2001). Modeling politics with economics tools: A critical survey of the literature. IMF Working Paper WP/01/10.

Peltzman, S. (1992). Voters as fiscal conservatives. Quarterly Journal of Economics, 107:327-361.

Persson, T. \& Tabellini, G. (2003). Do electoral cycles differ across political systems? IGIER Working Paper 232.

Rocha, F. \& Giuberti, A. C. (2004). Consenso político com relação à necessidade de disciplina fiscal dos estados: Um estudo da lei de responsabilidade fiscal. Dissertação de mestrado, ESAF. Monografia agraciada com o segundo lugar no IX Prêmio de Monografia do Tesouro Nacional. Tema Especial: Lei de Responsabilidade Fiscal (do site do Tesouro Nacional). 
Rogoff, K. (1990). Equilibrium political budget cycles. American Economic Review, 80:21-26.

Rogoff, K. \& Silbert, A. (1988). Elections and macroeconomic policy cycles. Review of Economic Studies, 55(1):1-16.

Romer, C. \& Romer, D. (2004). A new measure of monetary shocks: Derivation and implications. American Economic Review, 94:1055-1084.

Romer, C. \& Romer, D. (2009). The macroeconomic effects of tax changes: Estimates based on a new measure of fiscal shocks. American Economic Review, a sair.

Sakurai, S. N. (2005). Testando a hipótese de ciclos eleitorias racionais nas eleições dos municípios paulistas. Estudos Econômicos, 35(2):297-315.

Sakurai, S. N. (2009). Ciclos políticos nas funções orçamentárias dos municípios brasileiros: Uma análise para o período 1990-2005 via dados em painel. Estudos Econômicos, 39:39-58.

Sakurai, S. N. \& Menezes-Filho, N. A. (2008). Fiscal policy and reelection in Brazilian municipalities. Public Choice, 137:301-314.

Shi, M. \& Svensson, J. (2003). Political budget cycles: A review of recent developments. Nordic Journal of Political Economy, 29:67-76.

Wolfers, J. (2007). Are voters rational? Evidence from gubernatorial elections. Mimeo Wharton. 